\title{
Editorial: Seismic Vulnerability Assessment and Retrofitting of Building Structures
}

\author{
André Furtado ${ }^{1 *}$, Maria Teresa De Risi ${ }^{2}$ and Dipendra Gautam ${ }^{3}$ \\ ${ }^{1}$ CONSTRUCT-LESE, Faculty of Engineering, University of Porto, Porto, Portugal, ${ }^{2}$ Department of Structures for Engineering \\ and Architecture, University of Naples Federico II, Naples, Italy, ${ }^{3}$ Department of Civil Engineering, Institute of Engineering, \\ Kathmandu, Nepal
}

Keywords: earthquake engineering, RC buildings, masonry infill, seismic vulnerability assessment, seismic retrofitting, numerical modeling, experimental testing

\section{Editorial on the Research Topic}

\section{Seismic Vulnerability Assessment and Retrofitting of Building Structures}

Seismic risk is nowadays more pronounced throughout the active seismic regions, especially in densely populated areas with pre-code to substandard reinforced concrete (RC) building stocks as the dominant construction system. These deficiencies can be in structural and nonstructural elements. It is fundamental to note that RC buildings can have low-standard design and detailing than the current code provisions' demands. Therefore, $\mathrm{RC}$ frame buildings require seismic assessment and retrofitting, considering the non-linear behavior exhibited during an earthquake. Furthermore, accurate modeling strategies and seismic assessment methodologies are crucial to understanding existing buildings' behavior and developing adequate retrofit strategies to downsize seismic risk, as highlighted by the research papers collected within this Research Topic.

RC buildings that are poorly designed are likely to sustain shear damage and anchorage failure mainly when constructed with plain rebars as demonstrated by Melo et al.. They showed the importance of bond-slip effects to be considered in the numerical models of RC structural elements with plain reinforcement bars subject to significant seismic demands. They found that existing numerical models, generally calibrated for elements with deformed bars, cannot correctly capture the strength degradation and the pinching effect, especially for the columns with plain bars. They have proposed a modified tri-linear steel material model that considers the slippage of reinforcement bars by reducing the Young's steel modulus.

Additionally, RC buildings are generally comprised of masonry infill panels (made of bricks of blocks) used as enclosures. The standard practices and the international seismic codes still consider the infill panels as "non-structural elements," despite their pivotal role in the RC structures' seismic performance. However, the infill walls' contribution to the building's seismic performance can be favorable or not, depending on a series of phenomena, detailing aspects, and mechanical properties, such as the relative stiffness and strength between the frames and the masonry walls.

At a global level, the impact of infills in dynamic characteristics of infilled RC frames is reported by De Angelis and Pecce, and Dhakal et al.. De Angelis and Pecce performed a seismic assessment of a typical infilled RC frame building designed only for gravity loads constructed in 1960s in Southern Italy. The building's structural identification based on ambient vibration test pointed out the significant role of infill walls and partitions in the dynamic characteristics, which triggers the necessity of updating the numerical model coherently to include masonry infills' effects explicitly. They underline the impact of floor flexibility in RC building's dynamic behavior based on the results of a calibrated numerical model, including infills. Dhakal et al. identified dynamic characteristics

Front. Built Environ. 7:676584.

doi: 10.3389/fbuil.2021.676584
Citation:

Furtado A, De Risi MT and Gautam D (2021) Editorial: Seismic Vulnerability

Assessment and Retrofitting of Building Structures. 
of reinforced concrete frame buildings with brick infills representing typical Nepali construction through ambient vibration measurements in two four-storied buildings. They showed that an inaccurate estimate of seismic demand would have resulted if the flexibility of foundation and stiffness of infill walls are not considered as opposed to standard engineering practices.

The influence of infills on the seismic performance of RC buildings strongly depends on the type of infills. Existing RC buildings are generally characterized by relatively weak infills (e. g. belonging to "Group 4" per the Eurocode 6), usually thin, with a high slenderness ratio and a high percentage of voids. On the other hand, more recently, it is generally recommended to use stronger infills. Recent studies that consider thick infills, typically with low slenderness and relatively high mechanical properties, were reported by da Porto et al. based on comprehensive experimental campaigns. They presented an overview of the experimental results obtained by combined in-plane/out-of-plane (IP/OOP) tests on robust clay masonry infill walls.

It is guaranteed that the contribution of infills in seismic losses after an earthquake is undoubtedly remarkable. To this note, Del Gaudio et al. presented damage and loss estimation analyses considering some case studies of residential RC buildings that represent the pre 70s Italian and Mediterranean construction system. Resulting seismic damage and economic loss are obtained employing component-level loss estimation procedures. Some studies have addressed the critical aspects of reducing their vulnerabilities through experimental testing and numerical modeling considering life safety, especially when out-of-plane mechanisms become prominent. Some investigated techniques were the use of reinforcing bars (da Porto et al.), or of NearSurface Mounted (NSM) in mortar joints (Soti et al.), and application of fiber reinforced concrete mortar (FRCM) as highlighted by De Angelis and Pecce. da Porto et al. showed that vertical and horizontal reinforcement in masonry infill wall slightly reduces the IP damage and increases the IP strength. Such a system allows obtaining higher OOP capacity values and the more negligible impact of previous IP damage on the OOP response. It increases energy dissipation capacity and viscous damping ratio of the infills. Soti et al. presented the potential beneficial effects of a retrofit solution for unreinforced masonry infilled RC frames using NSM reinforcing steel bars. The proposed solution's feasibility was examined initially with a series of pull-out tests on NSM bars attached to masonry panels.
Then, the results from the pull-out tests were used to calibrate a 2D non-linear finite element modeling approach used to assess the effectiveness of the proposed retrofit solution, which gave rise to promising results in-plane lateral loads. De Angelis and Pecce depicted the beneficial effects of a strengthening solution that involves the infill panels as masonry walls cut from the RC columns to avoid the local interaction and strengthened by composite grids in mortar matrix (FRCM).

New infill typologies were studied by Milanesi et al.. Using the so-called "ductile" infills has shown promising results in recent experimental tests among the possible innovative techniques. They proposed calibrated macro-model approaches to demonstrate improved seismic behavior, thereby reducing RC framed structures' seismic vulnerability using ductile infills compared to traditional masonry infills.

Despite the effect of infills in RC frame buildings' seismic vulnerability, recent studies have shown promising results, especially in terms of checking the OOP mechanism. Some other profitable solutions to enhance masonry infills' seismic behavior, such as NSM, FRCM, and reinforcing bars, have provided a strong basis for seismic retrofitting of these elements.

\section{AUTHOR CONTRIBUTIONS}

AF: review and edition of the manuscript. DG and MD: writing and edition of the manuscript. All authors contributed to the article and approved the submitted version.

\section{ACKNOWLEDGMENTS}

This work was financially supported by: Programmatic funding - UIDP/04708/2020 of the CONSTRUCT - Instituto de I\&D em Estruturas e Construções - funded by national funds through the FCT/MCTES (PIDDAC).

Conflict of Interest: The authors declare that the research was conducted in the absence of any commercial or financial relationships that could be construed as a potential conflict of interest.

Copyright (c) 2021 Furtado, De Risi and Gautam. This is an open-access article distributed under the terms of the Creative Commons Attribution License (CC BY). The use, distribution or reproduction in other forums is permitted, provided the original author(s) and the copyright owner(s) are credited and that the original publication in this journal is cited, in accordance with accepted academic practice. No use, distribution or reproduction is permitted which does not comply with these terms. 